\title{
A preliminary flood-risk assessment of municipalities located in headwater basins of Slovakia based on the integrated approach
}

\author{
L. Solín, P. Skubinčan \& M. Madajová \\ Institute of Geography, Slovak Academy of Sciences, Slovakia
}

\begin{abstract}
The aim of preliminary flood-risk assessment, in general, is to identify the spatial variability of flood risk, which creates a rational basis for its detailed assessment and management. The traditional engineering approach to the evaluation of flood risk primarily aims to assess the ability of the river reaches to transport the discharge of the specified probability of non-exceedance. In this paper, the integrated approach addresses this scope. The flood-risk assessment of the municipalities situated in the headwater basins of Slovakia is based on a combination of flood hazard and expected negative consequences. The flood hazard in headwater basins is understood as a potential - that is, the disposition of the basin to suffer from flood - which is influenced, besides rainfall, by the attributes of the basin. The negative consequences are influenced by the vulnerability and resilience of the municipalities. Vulnerability is characterized by six proxy variables: the materials the houses are built from, the period in which they were built, the age structure of the population, ethnicity, completeness of the family and category of house. The ability of the municipalities to recover after a flood is expressed by the flood insurance rate. The municipalities are classified into five classes of flood risk based on the combination of variables reflecting the flood hazard, vulnerability and resilience. Keywords: integrated flood-risk management, flood risk, flood hazard, vulnerability, flood insurance, multi-criteria analysis.
\end{abstract}

\section{Introduction}

Currently, we are witnessing a change in paradigm of flood protection in many countries (e.g. Brown and Damery [1], Fuchs [2], Hassel [3]). From the 
exclusive application of engineering flood management (mostly by means of reducing the extent of flooding), flood protection gradually shifts towards integrated flood-risk management (APFM [4], Ale et al. [5]), which, in addition to reducing the scope of flooding, also focuses on the reduction of susceptibility to damage and mitigation of the impacts of flooding. The new paradigm requires a change of approach to the evaluation of flood risk.

The traditional engineering approach to flood-risk assessment constitutes specification of the magnitude of the discharges $Q_{\max }$ of the non-exceeding probability $F$. The preliminary evaluation primarily aims to assess the state of the river sections in municipalities (the shape, the size of the trough, and the stability of the banks) with regard to their ability to transport the flow rate of the specified probability of non-exceedance.

However, integrated flood-risk management addresses the assessment of flood risk in a more complex way. In addition to flood hazard, significant attention is paid to the assessment of the vulnerability of society to the floods. This change in the assessment of flood risk in particular reflects the change in the understanding of the concept of risk. Unlike the engineering approach that understands the concept of risk in relation to the threat of flooding only (flood risk $=$ flood hazard), integrated flood-risk management understands the risk as the expected losses (of lives, persons injured, property damaged, and economic activity disrupted) due to a particular hazard for a given area and reference period (UN [6]) and, therefore, flood risk = flood hazard*negative consequences. Flood hazard can be expressed in the form of probability (magnitude of a flood in terms of its non-exeedance probability) or in the form of potential (the possibility of the basin suffering from floods). The negative effects of a flood depend on the vulnerability of objects of the social, economic and environmental systems to floods in a given area (e.g. Wisner et al. [7], Messner and Meyer [8], Fuchs et al. [9]).

This paper deals with the preliminary integrated flood-risk assessment of municipalities located in the headwater basins of Slovakia. The aim of the preliminary flood-risk assessment is to identify the spatial variability of flood risk and thus to create a rational basis for its detailed assessment and management. Emphasis is laid on municipalities in small basins because Slovakia is a predominantly mountainous country (mountains account for nearly $60 \%$ of the total area of Slovakia). Almost $47 \%$ of all 2,928 municipalities are located in headwater basins in mountainous areas. In contrast, only $24 \%$ of municipalities are located in close vicinity to medium and large streams flowing in lowland areas. Nevertheless, an assessment of flood-risk management in small mountain catchments has not received sufficient attention. Flood management in Slovakia primarily aims to protect areas located along the middle and lower sections of the rivers in the lowlands with high concentrations of the population and economic activities. However, this preference for flood protection for residential areas located mainly in the lowland areas is not fully justified. In the period 1996-2006, 47\% of all municipalities in Slovakia were affected by flooding. Of these flood events, $67 \%$ occurred in the municipalities localized in small headwater basins (Solín [10]). In the small mountain river basins, flood 
hazard, in addition to watercourse flooding, is often also caused by the concentration of surface runoff in the slope areas during short but intense rainfall. Water which is on the surface of the soil gradually concentrates into ever larger streams and eventually gives rise to a large stream of water that rolls downhill and damages objects that are in its way.

Floods in small basins are therefore a significant phenomenon in Slovakia and corresponding attention must be paid to flood-risk management in these areas. Aware of this fact, we started to systematically work on the flood-risk assessment process, based on an integrated approach in municipalities located in headwater basins. First, a database of the attributes of small river basins was created in GIS (Solín et al. [11]). Second, the occurrence of flood events was added to the database (Solín [10]). Later, the effects of the basin attributes and land cover changes in the period 1990-2006 on the occurrence of flood events were analysed (Solín [12], Solín and Feranec [13]). The social vulnerability of the municipality populations with respect to floods was also evaluated (Solín [14]), as well as their ability to cope with the negative consequences of floods (Solín et al. [15]).

The aim of the article is to move to the integrated assessment of flood risks of municipalities located in small basins by the combination of results achieved in relation to the assessment of the individual components of flood risk.

\section{Data}

Preliminary flood-risk assessments of the municipalities located in headwater basins were created using the following data: a) a digital layer of boundaries of the headwater basins, b) a database of basin attributes, c) a digital layer of municipality centroids and boundaries, and d) a database of the socio-economic attributes of the municipalities. The digital layer of the headwater basins, which functions as the basic spatial unit, was created by Solín and Grešková [16], who modified the borders of the river basins which were digitized from the 1:50,000 scale water management maps by the Slovak Environmental Agency (SEA) in the period 1997-1998. The digital layer contains almost 4,587 small basins, with the areas of single basins varying from 0.04 to $150 \mathrm{~km}^{2}$. For the purposes of this study, a basic set of headwater basins was selected, which included 1,678 basins, mostly in mountainous areas of Slovakia, with a basin area in the interval of $5-150 \mathrm{~km}^{2}$. A database of their morphometric, geological and hydrological attributes, as well as soil texture parameters and characteristics of landscape cover was created, using the digital elevation model, CORINE Land Cover (Feranec et al. [17]), various digitized thematic maps and the outcomes of the processing of hydrological and rainfall data (Solín et al. [11]). A digital layer of the centroids and boundaries of the municipalities was provided by the SEA. Data used in the assessment process of the vulnerability of the economic and social systems of the municipalities were primarily the 2001 census data. The ability to cope with the negative consequences of floods and the capabilities of communities to restore their original state was expressed through the level of 
insurance against the risk of flooding. The data about flood insurance policies, along with data about flood insurance events was provided by the Allianz-Slovak Insurance Company.

\section{Flood-risk assessment methodology}

In general the conceptual and methodological framework of flood-risk assessment is based on a combination of the flood hazard and the vulnerability of the social, economic and environmental systems of a particular area. There are two groups of methods for determining the level of flood risk. The first group consists of methods expressing flood risk in an absolute way by average annual damage value (cf. FLOODsite [18]). Expressing flood risk in an absolute way combines the expected losses from all levels of hazard probability. The second group includes the method expressing flood risk in a relative way by ordinal scale, that is, dimensionless values of the flood hazard and the vulnerability of the economic, social and environmental systems are aggregated and then ranked into classes expressing high, moderate or low levels of risk. This process is the core of spatial multi-criteria decision analysis (cf. Malczewski [19, 20]). There are two types of multi-criteria decision analysis (MCDA): multi-attribute decision-making (MADM) and multi-objective decision-making (MODM).

In this paper, due to the fact that the research is carried out at the national level and the subject of an assessment is a set of 1,878 municipalities, the ordinal scale approach based on MADM was applied to assess flood risk. The following model represents this approach:

$$
U_{i}=\sum_{j} w_{j} u_{i j}
$$

where $U_{i}$ is the flood risk score of municipality ${ }_{\mathrm{i}}, u_{i j}$ is the standardized score of the variable ${ }_{j}$ corresponding to the flood hazard and vulnerability of the economic and social systems of municipality $\mathrm{i}_{\mathrm{i}}$ and $w_{j}$ is a weighting that represents the effect of variable ${ }_{j}$ on the flood risk.

Variables were standardized using the maximum score approach (Malczewski [20]). The transformation equation is:

$$
x_{i j}^{\prime}=\frac{x_{i j}}{x_{j}^{\max }}
$$

where

$x_{i j}^{\prime}=$ standardized score, $x_{i j}=$ criterion score, $x^{\max }=$ maximum criterion score

As far as the weighting of variables is concerned, the assumption that all variables have the same weight was adopted. Using this method, the value of the flood-hazard index and the value of the vulnerability index were determined. Their subsequent aggregation later formed the flood-risk index. 
Flood hazard can be expressed either on a probability or potential base. In the first case, the process of flood-hazard assessment constitutes specification of the magnitude of discharges $Q_{\max }$ of the non-exceeding probability $F$ and the mapping of the corresponding flooding. In the second case, the flood hazard is expressed by means of a potential - that is, the disposition of the basin to suffer from flood - which is influenced by the basin attributes of the basin (Weingartner et al. [21], Solín [12]). In this paper, we made the flood-hazard assessment on the basis of the basin potential. The flood hazard of the municipality is then derived from the flood-hazard potential of the basin in which the municipality is located. When deciding on the approach to the evaluation of the flood hazard, we took into account both the objective of the preliminary flood-risk assessment (the identification of the spatial variability of the flood risk) as well as the scale of the assessments (national scale), which led to choosing the potential-based form.

The flood vulnerability assessment expresses propensity to damage, resistance to flood and capacity of post flood recovery only in terms of the properties of the social, economic and environmental systems of the territory (Borden et al. [22], Cutter et al. [23], Tapsell et al. [24], Simpson and Human [25]). In this context, vulnerability means a potential. It does not contain the element of flood-hazard exposure; hence it is hazard-independent (Adger et al. [26], Damm et al. [27]). Vulnerability indices are established through a combination of normalized variables that characterize the vulnerability of the economic and social systems of municipalities.

\section{Results}

\subsection{Assessment of the flood hazard}

The evaluation of a basin's potential for the occurrence of a flood is based on the analysis of hydrographs. Fig. 1 shows the hydrographs of the average daily flow of two river basins, which are different in terms of their attributes. The hydrograph in fig. 1a is from the river basin geologically dominated by flysch rocks, that is, the dominant drainage process in this basin is direct runoff (BFI - base flow index $=0.26$ ) which usually creates sudden and steep flow waves. On the contrary, fig. $1 \mathrm{~b}$ represents a basin dominated by crystalline slate, and suggests that the predominant drainage process in this river basin is basic runoff $(\mathrm{BFI}=0.68)$. For this form of runoff typical flow waves are shallow and long lasting.

From this different hydrological response we can conclude that the flood threat in the first basin is much higher than that in the second. The results of the work of Solín [12] have shown that the permeability of the soil texture has the most significant impact on the hydrological response of all basins' attributes. The permeability of the soil texture of the river basin was established on the individual percentage of each soil texture class within the basin area. The second attribute that affects the hydrological response is deforestation of the basins. 


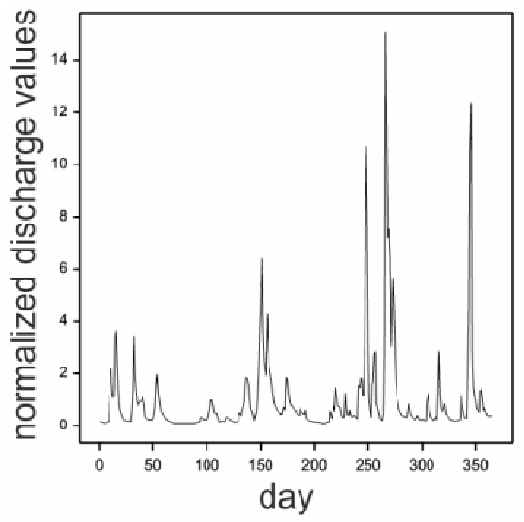

a)

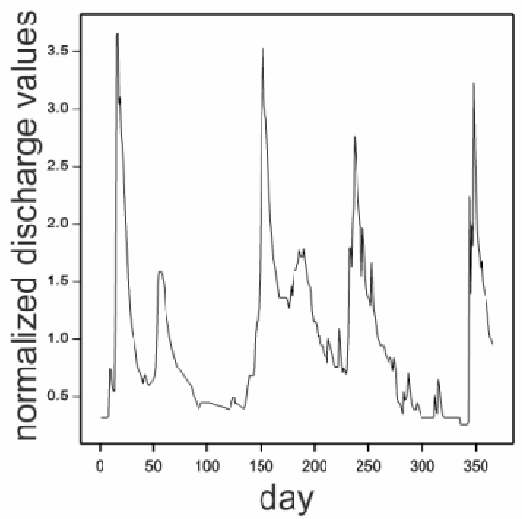

b)

Figure 1: Examples of different hydrological responses a) River Ladomírka, b) River Rimava.

While testing the different combinations of both attributes, it was proven that the optimal grouping of headwater basins is into three regional flood-hazard classes. Each class was assigned by ordinal values of flood hazard: 3 as high, 2 as medium, and 1 as low. Standardized ordinal values reflect the flood-hazard index. By overlaying the layer of flood-hazard classes of the basins with the layer of centroids representing individual municipalities, we were able to establish the level of flood hazard for each municipality (corresponding to the flood-hazard index of the basin in which it was located) (fig. 2).

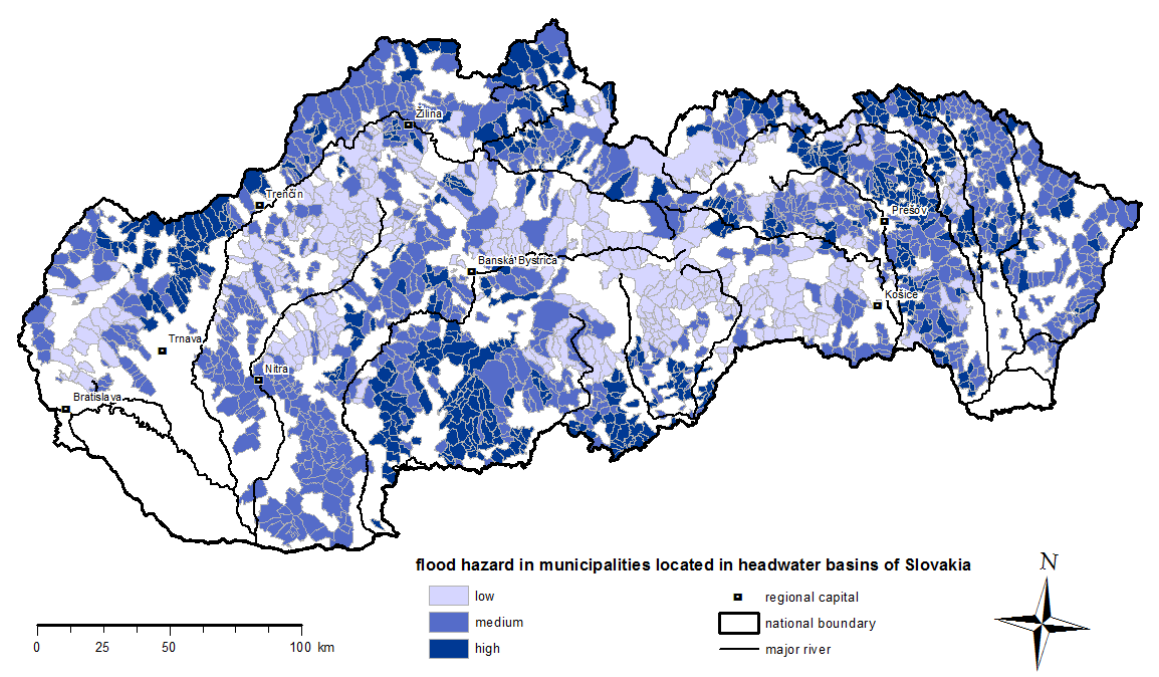

Figure 2: Flood hazard of municipalities located in headwater basins. 
The diversity of the hydrological responses as a result of the basin attributes is reflected in the different frequencies of the flood events in the municipalities (fig. 3). A flood event occurs when the mayor of the municipality announces a $3^{\text {rd }}$ degree flood alert.

\subsection{Assessment of the social and economic vulnerability}

The assessment of the three components of the vulnerability to floods, that is, the susceptibility of the economic system to damage, the resistance of the social system to floods, and their capacity for recovery after the flood is based on the results achieved by Solín [14] and Solín et al. [15]. In the first paper, the social and economic vulnerability to flooding of the Basic Settlement Units (BSU) is analysed. For the purpose of this study, BSUs were aggregated into higher territorial units - municipalities.

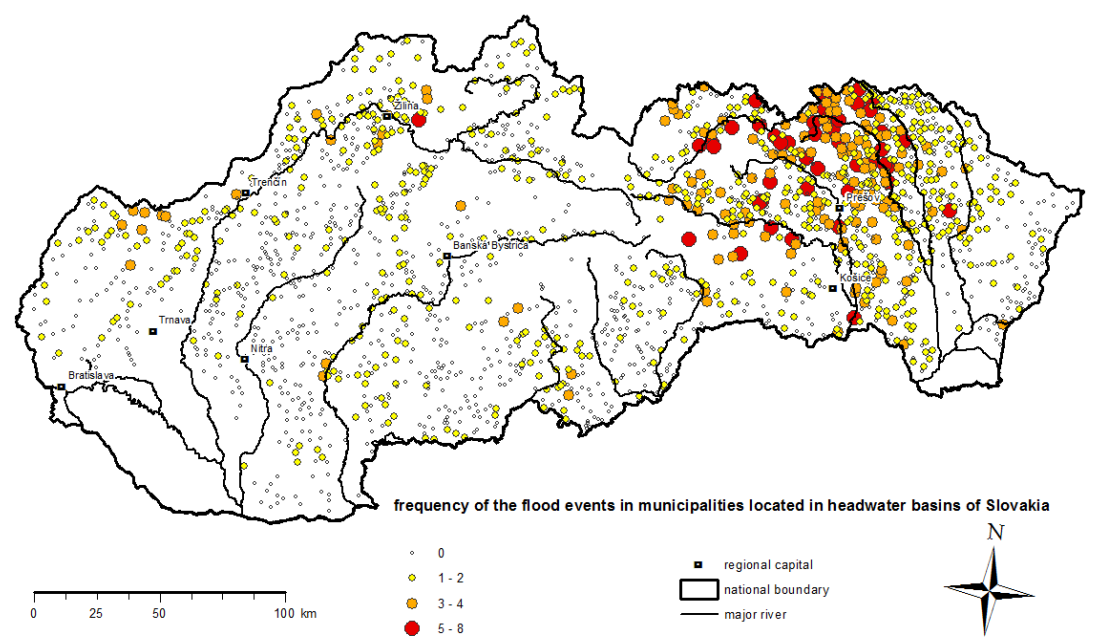

Figure 3: Frequency of the flood events in municipalities in the period 1996-2010.

Data on the variables and attributes of the economic and social systems used for vulnerability analysis are summarized in table 1.

Considering the materials the houses were built from and the year of construction of the family houses forms the economic system susceptibility index. A combination of three variables, age structure of the population, ethnicity and completeness of family, forms the social system resistance index. The capacity of municipalities to recover damaged property and return to their pre-flood state depends on the financial situation of the people living there. Financial deprivation was assessed indirectly using a categorization of the family houses in which people live. This variable is used to form the social system resilience index. By aggregating partial indices together we obtain an index of total vulnerability of the municipality to floods (fig. 4). 
Table 1: Proxy variables of economic and social vulnerability.

\begin{tabular}{|c|c|c|}
\hline System & Variable & $\begin{array}{c}\text { Attributes of variable } \\
\text { (percentage) }\end{array}$ \\
\hline \multirow[t]{2}{*}{ Economic } & Material of bearing walls & $\begin{array}{l}\text { Earthen houses, other and } \\
\text { unspecified materials }\end{array}$ \\
\hline & Date of construction & Houses before 1945 \\
\hline \multirow{4}{*}{ Social } & Age structure & People over the age of 65 \\
\hline & Ethnicity & Roma \\
\hline & Family completeness & Incomplete \\
\hline & Category of family house & $\begin{array}{l}\text { Houses of the } 3 r d \text { and } 4 \text { th } \\
\text { category }\end{array}$ \\
\hline
\end{tabular}

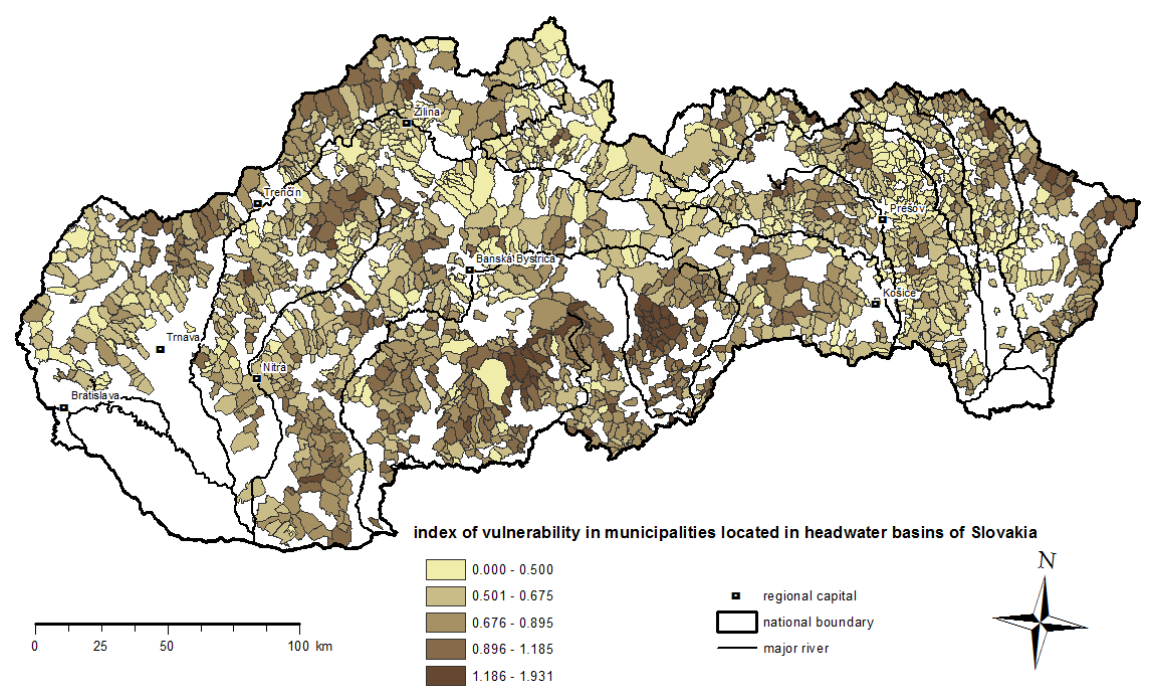

Figure 4: Vulnerability index of municipalities located in headwater basins.

The ability to cope with the negative consequences of the floods also depends on the level of insurance against damage caused by flooding. Empirical data on the flood-risk insurance of individual municipalities was analysed by Solín et al. [15]. In the past decade, a dramatic decrease in the population's interest in insuring their property against flooding has occurred. Only 58\% of policies active in 2002 were still in force in 2011. The mean level of properties insured against flooding in municipalities situated in headwater basins decreased from $60 \%$ in 2002 to $30 \%$ in 2011 . Apparently, these values have to be interpreted with some reserve, as in this case we were considering data from only one, although by far the largest, insurance company in the market. Considering the market share of other insurance companies in the field of non-life insurance, it can be presumed that the current overall level of flood-risk insurance in Slovakia 
is around $50 \%$. The insurance rate is expressed as the ratio of the number representing flood-risk policies in individual municipalities to the number of residential buildings (single-family houses and flats). Standardized values of the insurance rate form the index of flood impact mitigation (fig. 5).

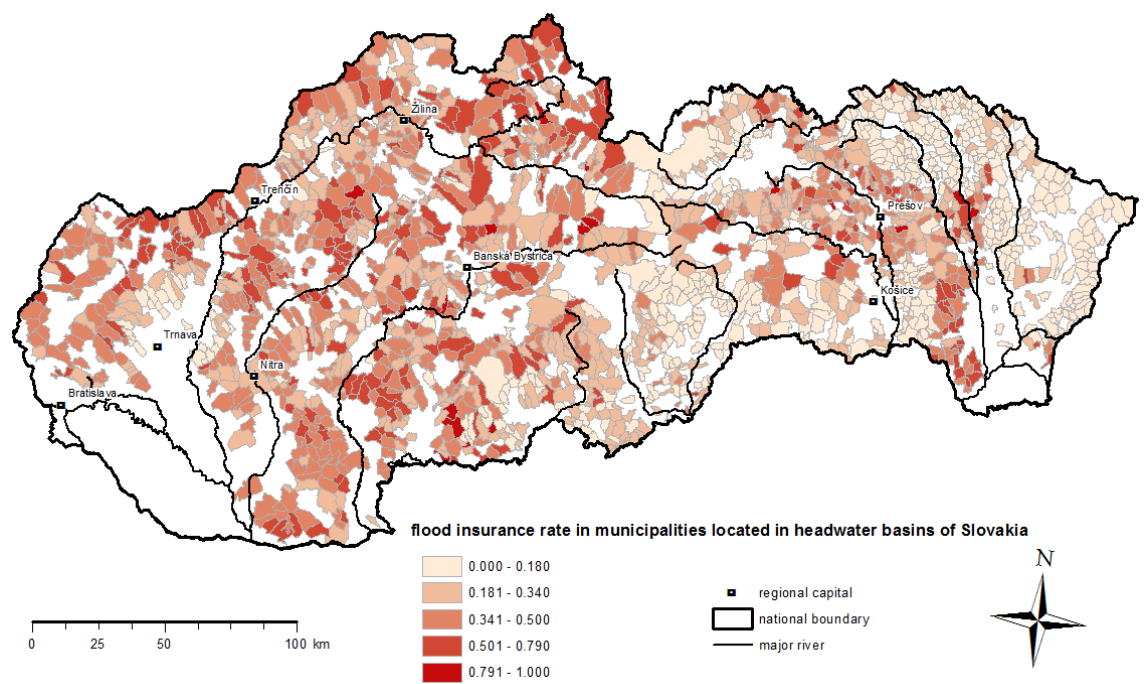

Figure 5: Flood insurance rate in municipalities located in headwater basins.

\subsection{Flood-risk assessment}

The level of overall flood risk is expressed by the index, which is the aggregate of the values of the indices reflecting flood hazard, vulnerability and level of insurance. Municipalities located in headwater basins were, according to the flood-risk index, classified into five ranks: very high, high, medium, low and very low levels of flood risk (fig. 6).

As already mentioned above, integrated flood-risk management is a combination of three primary strategies, which aim to reduce the extent of flooding, reducing vulnerability and mitigating the negative consequences of the floods. Flood-risk assessment based on an integrated approach is therefore a rational basis for the application of a spatially differentiated approach in designing the optimal strategy for flood-risk management plans. Share of the primary strategies within the framework of the optimal "general" strategy will depend on the level of flood risk. With the increasing level of flood risk, flood-risk management will move from the emphasis on the strategy eliminating the negative consequences of flood towards strategies reducing vulnerability and the extent of flooding. The specification of the optimal strategy for each class of flood risk is a significant step forward in the management of flood risks in comparison to the uniform application of the strategy reducing only the scope of flooding used in the traditional approach. 


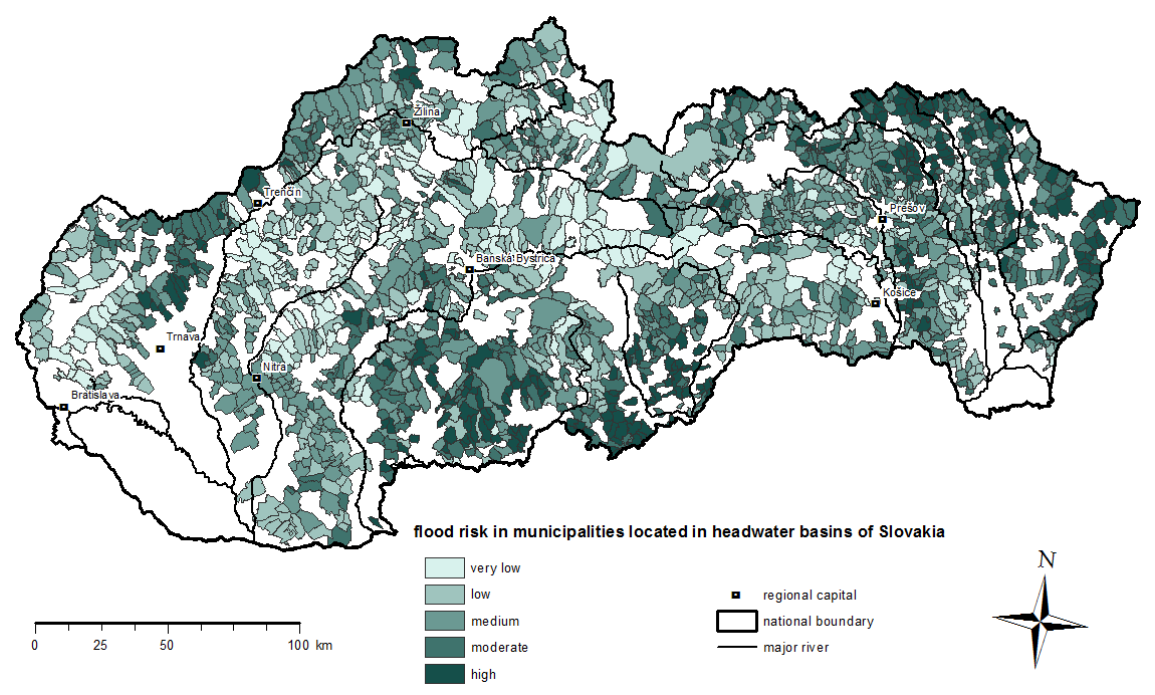

Figure 6: The level of flood risk of municipalities located in headwater basins.

The result of the preliminary integrated flood-risk assessment is an effective way to select areas for subsequent creation of probabilistic flood hazard maps and maps of flood risk, which are the basis for the assessment of the financial effectiveness of the proposed flood protection measures.

The expression of the results of the preliminary integrated flood-risk assessment, using the ordinal scale in comparison to the binary (yes/no) classification of the engineering approach, creates room to make flood-risk management exhaustive, that is, for each municipality an optimal flood management strategy can be determined based on its flood-risk level. In the case of a binary array of flood-risk assessment, the aim of flood-risk management concentrates only on municipalities with segments of river that have potentially significant flood risk, while neglecting other nearby municipalities with no potentially significant risk.

\section{Conclusions}

A shift in the flood protection paradigm from engineering flood management to integrated flood-risk management also requires a new approach to evaluate flood risk. Based on the integrated approach, in this article we have presented a preliminary flood-risk assessment of the municipalities located in headwater basins. Based on the mutual combination of the attributes of flood hazard, social and economic vulnerability and the ability to cope with the negative consequences of floods, municipalities were classified into five classes of flood risk. In comparison with the engineering approach, the results of the preliminary integrated flood-risk assessment create a much more efficient basis for the rational management of flood risk. 


\section{Acknowledgement}

This article is one of the outputs of the 2/0091 project Flood Risk in Communities of Slovakia, financially supported by the Scientific Grant Agency of the Ministry of Education, Science, Research and Sport of the Slovak Republic and the Slovak Academy of Sciences (VEGA).

\section{References}

[1] Brown, J. \& Damery, S., Managing flood risk in the UK: towards an integration of social and technical perspectives. Transactions/Institute of British Geographers, 27, pp. 412-426, 2002.

[2] Fuchs, S., Susceptibility versus resilience to mountain hazards in Austria paradigms of vulnerability revisited. Natural Hazards and Earth Systems Sciences, 9, pp. 337-352, 2009.

[3] Hassel, H., Risk and vulnerability analysis in practice: evaluation of analyses conducted in Swedish municipalities. Natural Hazards, 63, pp. 605-628.

[4] APFM (The Associated Programme on Flood Management), Integrated Flood Management. Concept paper. The Associated Programme on Flood Management, World Meteorological Organization and Global Water Partnership, Geneva, 2004.

[5] Ale, B., Aven, T. \& Jogejan, R., Review and discussion of basic concepts and principles in integrated risk management. Reliability, Risk and Safety: Theory and Applications, eds Briš, Guedes Soares \& Martorell, Taylor \& Francis Group: London, pp. 421-427, 2010.

[6] UN (United Nations), Internationally Agreed Glossary of Basic Terms Related to Disaster Management Risk. UN Department of Humanitarian Affairs, Geneva, 1992.

[7] Wisner, B., Blaikie, P., Cannon, T. \& Davis, I., At Risk: Natural Hazards, People's Vulnerability, and Disasters. $2^{\text {nd }}$ edition. Routledge: London, 2004.

[8] Messner, F. \& Meyer, V., Flood Damage, Vulnerability and Risk Perception - Challenge for Flood Damage Research. Umweltforschungszentrum Lepizig-Halle, Discussion papers 13, 2005.

[9] Fuchs, S., Bierkman, J. \& Glade, T., Vulnerability assessment in natural hazard and risk analysis: current approaches and future challenges. Natural Hazards 64, pp. 1969-1975, 2012.

[10] Solín, L., Analysis of floods occurrence in Slovakia in the period 1996-2006 (in Slovak). Journal of Hydrology and Hydromechanic. 56(2), pp. 95-115, 2008.

[11] Solín, L., Cebecauer, T., Grešková, A. \& Šúri, M., Small basins of Slovakia and their physical characteristics. National Report 2000 of the IHP UNESCO Project 1.1. FRIEND. Institute of Geography SAS, Slovak Committee for Hydrology. Bratislava, 2000. 
[12] Solín, L. Regional variability of flood threat in small basins of Slovakia (in Slovak). Geographical Journal, 63(1), pp. 29-52, 2011.

[13] Solín, L. \& Feranec, J., Land cover changes in small catchments in Slovakia during 1990-2006 and their effects on frequency of flood events. Natural Hazards, 56, pp. 195-214, 2011.

[14] Solín, L., Spatial variability in the flood vulnerability of urban areas in the headwater basins of Slovakia. Journal of Flood Risk Management, 5, pp. 303-320, 2012.

[15] Solín, L., Madajová, M. \& Skubinčan, P. Analysis of Commercial Flood Risk Insurance in Slovakia. (manuscript submitted for publication), 2013.

[16] Solín., L'., \& Grešková, A., Small catchments of Slovakia: basic spatial units of hydrogeographical regional division (in Slovak). Geographical Journal, 51(1), pp. 77-96, 1999.

[17] Feranec. J., Otahel, J. \& Pravda J., Land cover of Slovakia - identified by the CORINE land cover method (in Slovak). Geographia Slovaca 11. Institute of Geography, Slovak Aćademy of Sciences, Bratislava, 1996.

[18] FLOODsite, Guidelines for Socio-economic Flood Damage Evaluation. FLOODsite project Report number T9-06-01, 2006.

[19] Malczewski, J., GIS and Multicriteria Decision Analysis, John Wiley \& Sons, New York, 1999.

[20] Malczewski, J., GIS-based multicriteria decision analysis: a survey of literature. International Journal of Geographical Information Science, 20(7), pp. 703-726, 2006.

[21] Weingartner, R. Barben, M. \& Spreafico, M., Floods in mountain areas an overview based on examples from Switzerland. Journal of Hydrology, 282, pp. 10-24, 2003.

[22] Borden, A.K., Schmidtlein, M.C., Emrich, C.H.T., Piegorsch, W.W. \& Cutter, S.L., Vulnerability of U.S. cities to environmental hazards. Journal of Homeland Security and Emergency Management, 4 (2), pp. 1-21, 2007.

[23] Cutter, S.L., Boruff, B.J. \& Shirley, W.L., Social vulnerability to environmental hazards. Social Science Quarterly, 84 (2), pp. 242-261, 2003.

[24] Tapsell, S.M., Pennig-Rowsell, E.C., Tundtall, S.M. \& Wilson, T.L., Vulnerability to flooding: health and social dimensions. Philosophical Transactions of the Royal Society, 360, pp. 1511-1525, 2002.

[25] Simpson, D.M. \& Human, R.J., Large-scale vulnerability assessments for natural hazards. Natural Hazards, 47, pp. 143-155, 2008.

[26] Adger, N., Brooks, N., Bentham, G., Agnew, M. \& Eriksen, S., New indicators of vulnerability and adaptive capacity. Technical Report 7, Tyndall Centre for Climate Change Research, Norwich, 2004.

[27] Damm, M., Fekete, A. \& Bogardi, J.J., Intersectoral vulnerability indices as tools for framing risk mitigation measures and spatial planning. Conference Proc. HydroPredict 2010, Praha, CD ROM, 2010. 